\title{
Are We Living in a Converging World? Regional Disparities and Convergences from a Global Perspective
}

\author{
Petr Blizkovsky \\ Director for Economic and Regional Affairs \\ General Secretariat of the Council of the European Union \\ Rue de la Loi 148, 1048 Brussels, Belgium \\ E-mail: blizkovsky@yahoo.com
}

Received: April 2, 2012

Accepted: July 12, 2012

Online Published: September 7, 2012

doi:10.5430/rwe.v3n2p41

URL: http://dx.doi.org/10.5430/rwe.v3n2p41

\begin{abstract}
The aim of this study was to analyse regional disparity and convergence at a global level. Six global macro-regions were reflected: the EU, NAFTA, ASEAN, MERCOSUR, CIS and China. They represented $70 \%$ of global GDP and $65 \%$ of the global population. The disparities were measured for 223 micro-regions within three macro-regions (EU, NAFTA and China) and for 55 meso-regions (countries) within five macro-regions (EU, NAFTA, ASEAN, MERCOSUR and CIS). The study period was 2000-2008 (subject to availability of data). The methodology was based on the Gini coefficient, Disparity Range Coefficient (DRC), Average Disparity Range Coefficient (ADRC), and $\sigma$ - and $\beta$-convergence.

The results confirmed a mixed situation concerning the micro-regional disparity and its trend. These results suggested that the disparity levels varied considerably across the macro-regions from low to high. When disparity trends were calculated on GDP per capita, there were decreasing disparities in MERCOSUR, ASEAN and China. On the other hand, there was an increasing disparity trend in the EU and CIS. NAFTA showed only marginal fluctuations in this respect.

The convergence analysis results suggested that, based on the DRC analysis, none of the macro-regions converged. There were however differences. Five macro-regions diverged 1.4 to 12.68 times more quickly than the average macro-regional GDP per capita grew. This was the case for ASEAN, NAFTA, EU, China and CIS. MERCOSUR on the other hand diverged at a lower pace than the pace of macro-regional growth, namely at a rate of 0.52 . Based on the ADRC analysis, all macro-regions also proved to diverge. However, the divergence rates were much lower. Based on the $\sigma$-convergence analysis, two groups of macro-regions were identified. The converging macro-regions were NAFTA, ASEAN, China and EU. The rate of convergence was extremely low for NAFTA and somewhat higher for China (1.32\%) and ASEAN (1.4\%) and particularly high in the EU (3.5\%). There were two diverging macro-regions, MERCOSUR and CIS. The speed of divergence was $1 \%$ per year in both cases. Finally, based on the $\beta$-convergence analysis, two macro-regions converged - the EU and ASEAN. The annual rate of convergence was moderate, namely 1.32 and $1.9 \%$ for EU and ASEAN respectively. Slow divergence trends were registered for China, MERCOSUR, and especially in NAFTA $(0.14 \%)$, whereas the divergence trend for CIS was a bit higher at $1.25 \%$.
\end{abstract}

The results of the study did not confirm the hypothesis that the global macro-regions were converging in terms of GDP per capita.

Keywords: Disparity, Convergence, Regions, European Union, ASEAN, MERCOSUR, CIS, China

\section{Introduction}

We are living in a world which is more connected than it ever has been in history. Globalisation accelerated after the Second World War and more recently with new means of communications. But is the gain of globalisation distributed in a homogeneous way among regions? Are different parts of the world evolving at the same rate economically? Are we living in a world which is converging? These are the key questions of this study. 
The objective of the paper is to run a comparative analysis of the welfare disparities and convergences at the sub-national and national levels. The geographical scope covers six global macro-regions in Europe, Asia and America.

The research hypothesis to be tested by the study is that the regional disparities across the six macro-regions are converging. If confirmed, there would be both decreasing disparity and convergence inside each of the macro-regions. The study will aim at confirming this hypothesis.

The paper is built on three studies focusing on the regional disparities and convergence of each macro-region individually - one on the European regions (BLIZKOVSKY, P.; 2012a), one on the American regions (BLIZKOVSKY, P.; 2012b) and the last on the Asian regions (BLIZKOVSKY, P.; 2012c). The present study focuses on the global pattern on regional disparities and convergence emerging from the individual studies.

Looking at the literature, most of it focuses on individual disparities rather than on the disparities among regions (SUMMERS, R. (1995) and poverty issues (IRADIAN, G., 2005). A related question is whether or not the disparities are positive in the long term for the wealth trajectory of the given geographical unit. To the latter question there is no consensus in the literature. LUCAS, R.E. (2004) replies positively while CORDOBA, J.C., VERDIER, G. (2007) and IMF (1998) challenge such a conclusion referring to the large welfare cost of inequality, possibly higher than gains from economic growth.

There are many studies on the subject of disparities and economic growth, such as IMF (2007), SALA-I-MARTIN, X. (2006), UNDP (2008). However, as shown by EDERVEEN, S.; GORTER, J.; DE MOOIJ, R. and NAHUIS, R. (2002), we can conclude that the economic theory on the explanation of the fundamentals of mutual economic development among the different regions is not conclusive. The neo-classical theory suggests the natural catch-up effect as a dominant development force. Thus, the expected results would be a more equal distribution of wealth among regions. The new economic geography argues the opposite: the opening of the global economy results in further amplification of the competitive advantage through favourable location, low transaction cost, cluster effect of university-R\&D-skilled labour. Under this scenario we would witness a further concentration of economic activities to metropolises and the creation of a core-periphery pattern.

The disparities are the subject of extensive literature, but the evidence is fuzzed. The literature studying the disparities inside regions and regional convergence is as vast as the diversity of the individual cases. However, it does not put forward convincing, straightforward evidence and explanation.

Among the contributions suggesting regional convergence, BARRO, J, SALA-I-MARTIN, X. (1992), SALA-I-MARTIN, X. $(1995,2002,2006)$ suggested a non-linear $\beta$-convergence and $\sigma$-convergence at the national level for OECD countries within the time period of 1950 to 1990 . The convergence speed fluctuated over time with a slowing down in the less favourable growth periods. At the regional level, UNEL, B.; ZEBREGS, H. (2006) confirmed the convergence in the US, EU and Japan, and VILLAVERDE, J.; MAZA, A. (2009) for Spain, and for the sub-national level, DUFEK, J., MINAŘÍK, B. (2009) in the Czech Republic for the total employment rate, and KAUFMAN, M., SWAGEL, P.; DUNAWAY, S. (2003) in the case of Canada.

There are studies suggesting a divergent or mixed development by ATEN, B.; HESTON, A., (2003) who point out the importance of the methodological issue. OECD (2009) concludes that there is no evidence that the average GDP per capita converged among OECD regions in the period 1980-2005. An example of the partial convergent development is the study of Latin America by SERRA, M. I.; PAZIMO, M. F.; LINDOW, G.; SUTTON, B.; RAMIREZ, G. (2006). In the case of China, divergence was proved at the regional income level by BELL, M. W.; HOE EE KHOR, KALPANA, K. (1993), even though there were limited time periods of convergence registered. UNEL, B.; ZEBREGS, H. (2006) studied the regional developments in labour productivity in China's provinces in the period between 1978 and 1998 and concluded that there was no absolute convergence. On the other hand, they found evidence for convergence in production efficiency. In the case of Russia, DABLA NORIS, E., WEBER, S. (2001) suggest that the regional GDP disparities of its 89 regions increased in the period between 1992 and 1997. This trend is explained by the authors by the change in economic and policy structures. Similarly for Slovakia, BANERJEE, B.; JARMUZEK, M. (2009) studied the regional GDP per capita, labour productivity and labour utilisation development and concluded that from 2000 to 2006 there was a widening of the disparities.

\section{Methodology}

The six macro-regions under scrutiny were the European Union (EU), North American Free Trade Agreement (NAFTA), Association of Southeast Asian Nations (ASEAN), Common Southern Market (MERCOSUR), 
Commonwealth of Independent States (CIS) and People's Republic of China. They correspond to roughly $70 \%$ of the global economy and half the global population (see Table 1).

$<$ Insert Table 1 Here>

Below is a summary of the key methodological parameters. The details are in BLIZKOVSKY, P. (2012 a-c).

On regions: The study analyses in total six macro-regions, 55 meso-regions (countries) and 223 micro-regions (see Table 2). In the case of the EU, there are 27 Member States at the level of meso-regions. The 97 micro-regions in the study are represented by 97 Nomenclature of Territorial Units for Statistics, NUTS 1 (EUROPEAN UNION, 2003). Due to EU enlargement, the 15 EU Members are covered until 2002, the 25 EU Members between 2002 and 2003, and the $27 \mathrm{EU}$ Members since 2004. The data on the EU are based on the European Commission (Eurostat) source. For NAFTA, there are 95 micro-regions (12 in Canada; 32 in Mexico and 51 states in the US). The micro-regions are based on the OECD statistical classification. The meso-regions are represented by the three NAFTA countries (Canada, Mexico and the USA). In the case of the MERCOSUR macro-region, the regions are represented by four countries (Argentina, Brazil, Paraguay and Uruguay) as the necessary data was not available at the micro-regional level. In the case of the ASEAN and CIS macro-regions, the regions were represented by 10 and 11 countries respectively - no sub-national comparable data were available. In the case of the China macro-region, the regions were represented by 31 provinces.

$<$ Insert Table 2 Here>

On data: The time period of the study is 2000-2008 except for Mexico where it is 2000-2005 due to the low availability of data. For the EU the data source was Eurostat http://epp.eurostat.ec.europa.eu/portal/page/portal/statistics/themes). The NAFTA data was taken from the OECD (http://stats.oecd.org/index.aspx), for ASEAN, MERCOSUR and CIS it was the IMF's World Economic Outlook Database 2009 (Note 1) and for China it was taken from the Chinese National Bureau of Statistics where the GDP per capita are missing for the years 2001 and 2002. The data on GDP in the purchasing parity power (PPP) were considered in all regions, with the exception of the EU where a similar characteristic of purchasing parity standard (PPS) is used by Eurostat, and in the case of China where the PPP has little economic sense as the whole macro-region is a single currency area.

On coefficients and indices: To evaluate regional disparities, the Gini coefficient was calculated using free online software (http://wessa.net/co.wasp). The Gini coefficient was calculated on nominal GDP, GDP per capita and GDP per capita PPS.

To analyse convergence, four methods were used based on GDP per capita. First two of them, the Disparity Range Coefficient (DRC) and Average Disparity Range Coefficient (ADRC), were built upon a regression analysis. The regression was constructed in such a way as to capture to what extent the distribution of income at the micro-regional level is affected by changes in the macro-regional GDP over a sample period. The regression coefficient $c_{2}$ indicates the slope of the regression line between two variables. The DRC is defined, for a particular year, as the difference between the maximum and minimum values of GDP per capita of the micro-region data for the year in question. The ADRC for a particular year is calculated analogically but, instead of the difference between the maximum and minimum values, it calculates the arithmetic mean of the sum of all distances (in absolute terms) between the GDP per capita of the macro-region and all the values for the corresponding micro-regional GDP per capita for the year. Regarding the ADRC for the national level, it is derived as the arithmetic mean of the sum of all distances between the national GDP per capita of the country under scrutiny and all the corresponding micro-regional GDP per capita of the same state (BLIZKOVSKY, P; 2012). Additionally, two other standard convergence tools of $\sigma$ and $\beta$-convergence were used (for details, see ŽIVĚLOVÁ, I.; PALÁT, M.; 2008 and DUFEK, J., MINAŘÍK, B.; 2009).

\section{Results and Discussion}

\subsection{Disparity Results}

In each macro-region, we have results for three Gini coefficients. The first, based on nominal GDP, measures the absolute disparities between micro-regions. It is important to bear in mind that this measure indicates more the size of the micro-region rather than the level of individual output per capita. The second measure is based on GDP per capita. This is arguably the most relevant for the disparity analysis as it refers to the relative micro-regional output derived per capita. Third, we set up an analysis based on the individual GDP in purchasing power parity. This is more relevant for an international comparison and adds the factor of price and income to the whole picture. 
The disparity analysis was based on nominal GDP. The Gini coefficient had high values in all cases. This indicates the fact that there are important differences in the absolute economic size of micro-regions in the macro-regions. The macro-regions can be split into three groups.

The lowest disparity was established for China and the EU with the Gini coefficient below 0.5. This suggests that there is more homogeneity around their micro-regions. Interestingly, it could also be an indicator of the potential for political cooperation of the micro-regions inside the macro-region, as the differences among them are not extremely high. It is worth noticing that in both cases the political integration is high, as China is a sovereign country and the EU a macro-regional organisation with the highest level of shared economic and political sovereignty. In other words, the Gini coefficient below 0.5 was found for the macro-regions sharing their sovereignty. Whether it is an attribute for closer cooperation, the results would need to be analysed separately. The methodological factor also plays a role, namely the fact that in both cases the number of micro-regions under scrutiny is high.

A mid-level disparity, at around 0.5 to 0.65 , was found for MERCOSUR, ASEAN and NAFTA. This confirms a high level of micro-regional heterogeneity with some economically important and other less important micro-regions.

The highest disparity level was recorded for the CIS, with the Gini coefficient close to 0.80 . Thee CIS is therefore a macro-region whose meso-regions have an extremely high disparity of nominal output.

$<$ Insert Table 3 Here $>$

The second disparity analysis was run based on GDP per capita (Table IV). This can be considered as the core one for evaluating the relative disparity among the regions. The levels of disparity, measured by the Gini coefficient, are much lower here, roughly half or less compared to the nominal GDP measure. This tells us that the real individual disparities among the micro-regions of a given macro-region are lower than the absolute output disparities.

Similarly as in the previous exercise, we can divide the macro-regions into three groups.

The lowest disparity, below 0.3, was found for the EU and MERCOSUR. This is an interesting result. The EU figures were expected but the MERCOSUR outcome is surprising. The relatively low individual outcome disparities among the MERCOSUR meso-regions indicate low differences among the meso-regions. On top of that, there was a strong trend towards less meso-regional disparities in MERCOSUR, while in the EU the disparities were widening, most probably due to EU enlargement. An active regional policy could have played a role in keeping the regional disparities at low levels.

The mid-level disparity, between 0.30 and 0.42 , was recorded for three macro-regions: China, CIS and NAFTA. This indicates that per capita micro-regional disparities are relatively high there. Nevertheless, in all three cases the disparities at the end of the observed time-period were lower than at the beginning. The explanation for closing down disparities is complex. In the case of China, there is a strong regional policy to ensure the economic and social cohesion of the country. In the case of NAFTA, the response is probably more on the side of free market economy forces, while in the CIS the leading factor could be the historical economic basis inherited from the USSR.

The highest disparity level was confirmed for ASEAN, with the Gini coefficient close to 0.70. ASEAN is therefore a macro-region whose meso-regions have an extremely high disparity of per capita output.

$<$ Insert Table 4 Here $>$

The third disparity analysis was based on the GDP per capita in PPP or PPS (Table V). This analyses the individual micro-regional output while taking into account the price and income levels. Thus, this measure is the most relevant in terms of social consequences for the micro-regions. Overall, the levels of disparity measured by the Gini coefficient are the lowest of all three exercises. With some exceptions, the trends correspond to those of the GDP per capita calculations.

The lowest disparities, between 0.15 and 0.20 , were calculated once again for the EU and MERCOSUR. This confirms the previous findings. The fact that the levels are even lower using the PPS/PPP adjustment for the per capita GDP proves that the price and income levels among the micro-regions further reduce the disparity levels. The trend was towards more disparity in the EU, due to EU enlargement, and towards less disparity in MERCOSUR.

The mid-level disparity, between 0.30 and 0.35 , was recorded for the same three macro-regions - China, CIS and NAFTA - as in the previous analysis. This stipulates further that the disparity pattern is confirmed. All three macro-regions have medium disparity levels and the price and income factor reduce them down further. 
The highest disparity level was confirmed for ASEAN, with the Gini coefficient around 0.65. ASEAN is therefore a macro-region whose meso-regions have an extremely high disparity of per capita output even when the PPP is taken on board.

$<$ Insert Table 5 Here>

The overall disparity results are summed up in Table 6. It shows the results for the Gini coefficient for the three measures from the lowest to the highest disparity.

$<$ Insert Table 6 Here $>$

By way of generalisation, the macro-regions with the lowest disparities were MERCOSUR (based on GDP per capita and GDP per capita in PPP/PPS), closely followed by the EU. The highest disparities were calculated for ASEAN and CIS

This overview stimulates further reflection about the interlinks between macro-regional disparities and the nature of the macro-regions. If we compare the macro-regional GDP per capita with the disparity level, we can observe a certain tendency that, the higher the GDP per capita goes, the lower the micro-regional disparities based on individual output are. This stylised model can be confirmed by the results for the EU, the richest macro-region in terms of GDP per capita, which exhibits low disparity ranking. Inversely, ASEAN, the poorest among the macro-regions, is the leader in disparity. However, this conclusion does not apply to NAFTA. The remaining macro-regions follow the same model in the middle of the ranking. It is worth noting that MERCOSUR ended up as the macro-region with the lowest disparities in per capita GDP and in per capita GDP in PPP, while being only the third macro-region in terms of GDP per capita. This was mainly due to the decreasing disparity trend in MERCOSUR and the increasing one in the EU. Nevertheless the detected pattern of higher GDP per capita corresponding to lower disparities is still present.

There is no such a relation between population and disparity. On the basis of the analysis made, we cannot claim that more populated macro-regions record more disparity.

There seems to be a negative link between the level of political and economic cooperation in the macro-region and its disparities. Whether it is a cause of effect, it cannot be verified, as it goes above the aim of this study. However, such an overall tendency is supported by the results of the EU and NAFTA on the one hand, and ASEAN and CIS on the other. MERSOSUR is an exception to this observation with its medium level of cooperation and low disparities.

\subsection{Convergence Results}

The results from four different methods are available in Table VII.

First, we analyse the convergence that resulted from the DRC. In this case we compare the regression between the extreme micro-regional gap and macro-regional growth. Based on the DRC analysis, none of the macro-regions under scrutiny converged. There were however differences. The first group, represented by MERCOSUR, diverged at a lower pace than macro-regional growth, namely at a rate of 0.52 . This means that the micro-regions are diverging but at a lower rate than the average macro-regional GDP per capita is growing. The second group consisted of CIS, China, EU and NAFTA. For this whole group, an increase of 1000 currency units of macro-regional income per capita entails that the gap between the poorest and richest micro-region increased by 1400 in CIS, 2370 in China, 6990 in the EU and 6260 in NAFTA. The results are statistically significant. The last group is ASEAN. Its $c_{2}$ parameter was more than 10 , namely 12.65 . This represents an extremely high divergence trend, which is in addition statistically significant.

Second, we analyse the convergence resulting from the ADRC. In this case we compare the regression between the average micro-regional gap and the macro-regional growth. The first conclusion is that once again divergence was recorded for all macro-regions, meaning that even the average distance between micro-regions rises as the macro-regions grow. However, the divergence rates are much lower than the ones derived from the DRC regressions, due to the fact that the DRC regressions were based on the extreme values (minimums and maximums) of the micro-regional data, while the ADRC regressions were based on averages, which smoothes the results. We can split the macro-regions into two groups: those with a $c_{2}$ parameter below 1 and with the $c_{2}$ parameter above 1 . The first group with a small divergence rate is represented by the EU, MERCOSUR, China, NAFTA and CIS. All those macro-regions exhibited a divergence between the average output micro-regional gap and macro-regional growth. However, this divergence was smaller than macro-regional growth $\left(c_{2}\right.$ parameter lower than 1$)$. We can therefore note that the divergence is moderate in this group. The second group is represented by the macro-region ASEAN only. Its $c_{2}$ parameter was 2.98. ASEAN thus appeared as a diverging macro-region. 
Third, we proceed towards the $\sigma$-convergence. By doing this, we evaluate whether the standard deviation of the annual micro-regional data converges or not. Overall, we note that the annual rates were low. In all cases the annual convergence or divergence was below $2 \%$. With this we can state that the output changes inside the regions are relatively small. Concerning the trend, we can establish two groups of macro-regions: converging and diverging ones. Among the converging macro-regions are ASEAN, China and EU. There is also a negligibly low rate of convergence for NAFTA $(0.01 \%)$. The convergence rate in the EU was higher. The surprising results are offered by ASEAN. Contrary to the DRC and ADRC analysis, it is the most converging macro-region of all. This result is even statistically explained by the given regression. This documents the methodological comment made at the beginning of this chapter concerning the different perspective offered by specific convergence analysis. There were two diverging macro-regions identified, MERCOSUR and CIS. The annual speed of divergence was relatively high in MERCOSUR and CIS - 1\% in both. Anyhow, this trend is interesting mainly in the case of MERCOSUR which was the least diverging macro-region based on DRC and ADRC. Anyhow, the statistical relevance of the result is not straightforward.

Fourth, we address the $\beta$-convergence results. The results go in the same direction as in the case of the $\sigma$-convergence. For all but one macro-region, the same orientation of trend was detected. However the intensity of convergence or divergence differs. In the converging macro-regions, ASEAN and China, the rate of convergence was low and below $1 \%$. The EU demonstrated very a high convergence at an annual rate $3.50 \%$. A diverging trend was captured for MERCOSUR and CIS, with an annual rate of $1.00 \%$ in both macro-regions. On top of that the NAFTA macro-region was a special case with a statistically insignificant, unclear status quo trend.

$<$ Insert Table 7 Here $>$

In conclusion, the following can be said on the convergence analysis. The methods chosen offer different perspectives. The ones based on DRC and ADRC tend to be more divergence-oriented. This can be explained by the fact that they focus on the micro-regional gaps rather than on the whole GDP per capita values. Therefore, those methods can be seen as a sort of more detailed tool to evaluate the disparity trend and consequently the convergence.

Inside the four methodological methods, the two approaches tend to offer similar trends, although the speed of the processes differs. The analysis based on DRC and ADRC detected a divergence trend for all macro-regions. The rate of divergence was however more pronounced in the case of the DRC analysis. The $\sigma$ - and $\beta$-convergences also offer mutually compatible results with the differentiation of speeds.

In conclusion, on the convergence analysis, for the three macro-regions NAFTA, MERCOSUR and CIS, there is a divergence trend confirmed. In the case of NAFTA, there is a marginal convergence noted in the case of $\beta$-convergence which could be ignored. For the three other macro-regions - EU, ASEAN and China - the four convergence methods offer a more diverse picture.

Let us proceed to the concise presentation of both the disparity and convergence analysis. The results obtained are summarised in Table 8.

$<$ Insert Table 8 Here $>$

The above outcome represents an overall result of both disparity and convergence analysis. The results of the study suggest that there is no clear trend towards disparity decreasing and thus regional convergence. Therefore the tested hypothesis was not confirmed.

\section{Discussion}

The results obtained can be discussed in two ways - from a methodological perspective on the consistency between the methods used, and in terms of the consistency of our results with the results of other studies.

Starting with consistency, the results obtained can be seen as largely consistent. In the nominal GDP analysis, the results suggest that the micro-regions within the macro-regions are of significantly different economic weight. This is demonstrated clearly by the disparity analysis based on the nominal regional GDP. This became clear mainly for the macro-regions, such as ASEAN, which has a small number of rich micro-regions. Another sign of consistency of the disparity analysis based on the nominal GDP is the inverse correlation between the macro-regional wealth and its micro-regional disparities. It is to be noted that the order of nominal GDP of the macro-regions in ascendant order is inversely proportional to a certain extent to that of the nominal regional disparities. In other words, the richer the macro-region is, the lower its micro-regional disparities are. In the per capita GDP analysis, the results are more complex. The reason for this is that the individual output per capita of the micro-regions is a more complex parameter than nominal GDP, as it reflects the completive strength of the micro-regions. The results are largely 
consistent in the sense that the Gini coefficient values are in all but one case much lower than the Gini coefficient values for the nominal disparity analysis. However, ASEAN is an exception. In this case the per capita disparity results are even higher than the nominal ones. The reason for this is the exceptionally high GDP per capita of Singapore and Brunei Darussalam.

If we look at the macro-regional GDP per capita level and compare it with the disparity analysis results of its micro-regions, the consistency is also less present here. We cannot generalise the results as in the above case. It is true that there is a similar somewhat inverse relation for the majority of regions suggesting that, the higher the GDP per capita in the macro-region, the lower the micro-regional disparities. This was confirmed for the EU, MERCOSUR, ASEAN, and to a more limited extent CIS. However there are exceptions such as China which is a relatively low-output-per-capita macro-region but its micro-regional disparities are reasonably small, and NAFTA which has very high output per capita, but nevertheless quite big micro-regional disparities. These anomalies from the general pattern reflect reality rather than a methodological problem. From this perspective the results provide a consistent outcome. In the GDP per capita in PPP/PPS analysis, the consistency of the results is very similar to the previous case. The general pattern is that this analysis offers the smallest levels of Gini-coefficient values out of all three methods. The reason for this has an economic logic, based on the purchasing parity power corrections of the income levels.

Looking at these disparity results based on four different approaches, the results here are only marginally consistent.

If we look at the results reached using the classical methods of the $\beta$ - and $\sigma$-convergence together, we see relatively mixed results, namely convergent results of the analysis both for the EU and ASEAN. In both macro-regions, the tendency is the same based on these two methodological approaches. Only the values for the speed of convergence/divergence vary. On the other hand, both methods detect divergence trends for MERCOSUR and CIS. In the case of the remaining two macro-regions, the results were only marginally inconsistent in NAFTA (both results suggested no clear trend) and provided mixed results for China. The inconsistency in this particular case can be explained by the lack of data series and a high differentiation of the macro-regional GDP per capita levels.

Regarding the convergence results obtained by the DRC and ADRC, regressions confirm that they are mutually consistent. For several macro-regions, the trend is identical and the speed of the divergence process is comparable.

The $c_{2}$ parameters of the regression functions of the DRC and ADRC are highest for the macro-region ASEAN.

Middle values were calculated for China and NAFTA. The lowest divergence trend was identified with both methods for MERCOSUR.

However, the results of the convergence analysis of the $\beta$ - and $\sigma$-convergence and the DRC and ADRC regressions are not mutually compatible, as $\beta$ - and $\sigma$-convergences suggest more convergence-like results and DRC and ADRC regressions point to divergence trends only. However, this diverse interpretation could be turned into an advantage by offering more insight into the real processes of the convergence of micro-regions. By its construction, the DRC and ADRC are more 'divergence' sensitive as they are constructed on disparities - average or absolute- among the regions.

Second, how do the results fit with the outcomes of other studies? Relatively well - although the bulk of the theoretical analyses were carried out for individual disparities in the regions and not for the disparities among regions. However, DOMINGUEZ, J.; NUNEZ J. (2003) confirm that the disparities decreased in the EU before enlargement. This would also be our conclusion. Our results can also confirm the general conclusion of IRADIAN, G. (2005) who claims that the disparities have a tendency to decrease once a certain level of economic development is reached. We are also in concordance with DAS, G. G. (2007) concerning the decreasing of disparities as a function of economic development.

The picture becomes more diverse when we compare our results with the literature on the convergence analysis. Here, our study offers basically two interpretations of reality. As described above, based on the methodology, one is more convergence-oriented, the other more divergence-oriented.

Therefore, our analysis of the $\beta$ - and $\sigma$-convergences corresponds to the findings of several studies, such as BARRO, J, SALA-I-MARTIN, X. (1992), DUFEK, J., MINARIK, B. (2009), KAUFMAN, M., SWAGEL, P.; DUNAWAY, S. (2003), SALA-I-MARTIN, X. (1994a, 1994b, 1994c, 1995, 2002, 2006) and UNEL, B.; ZEBREGS, H. (2006). 
On the other hand, our divergence and mixed scenarios, based on DRC and ADRC regressions, concord with the outcome of BANERJEE, B.; JARMUZEK, M. (2009), BELL, M. W.; HOE EE KHOR, KALPANA, K. (1993), DABLA NORIS, E., WEBER, S. (2001) and OECD (2009).

\section{Conclusions}

The results of the study suggest that the disparity levels varied considerably across the macro-regions from low to high ones. There was a pattern suggesting, with the notable exception of MERCOSUR, that the macro-regions with high GDP level had lower regional disparities. With respect to disparity trends based on nominal GDP, three patterns were detected. There was an increasing disparity trend in the EU, CIS and MERCOSUR. A slightly decreasing disparity trend occurred in NAFTA. Finally, there were only marginal fluctuations in ASEAN and China. When disparity trends were calculated on GDP per capita, there were decreasing disparities in MERCOSUR, ASEAN and China. On the other hand, there was an increasing disparity trend in the EU and CIS. NAFTA showed only marginal fluctuations in this respect. Finally, if measured by GDP per capita in PPP/PPS, the disparities dropped in a limited way in ASEAN, increased in MERCOSUR, fluctuated without a clear trend in the EU and showed only marginal changes in NAFTA and CIS.

The convergence analysis results suggest that, based on the DRC analysis, none of the macro-regions converged. There were however differences. Five macro-regions diverged 1.4 to 12.68 times more quickly than the average macro-regional GDP per capita grew. This was the case of ASEAN, NAFTA, EU, China and CIS. MERCOSUR on the other hand diverged at a lower pace than macro-regional growth, namely at a 0.52 rate. Based on the ADRC analysis, all macro-regions also proved to diverge. However, the divergence rates were much lower. The macro-regions EU, MERCOSUR, China, NAFTA and CIS discovered that their divergence was slower than macro-regional growth, thus their divergence was moderate. On the other side, ASEAN appeared as a highly diverging macro-region with a divergence rate of 2.98. Based on the $\sigma$-convergence analysis, two groups of macro-regions were identified. The converging macro-regions were NAFTA, ASEAN, China and EU. The rate of convergence was extremely low for NAFTA and somewhat higher for China (1.32\%) and ASEAN (1.4\%) and particularly high in the EU (3.5\%). There were two diverging macro-regions, MERCOSUR and CIS. The speed of divergence was $1 \%$ per year in both. Finally, based on the $\beta$-convergence analysis, two macro-regions converged, the EU and ASEAN. The annual rate of convergence was moderate, namely 1.32 and $1.9 \%$ for the EU and ASEAN respectively. Slow divergence trends were registered for China, MERCOSUR and especially NAFTA (0.14\%), whereas the divergence trend for CIS was a bit higher at $1.25 \%$.

Returning to the hypothesis of the study, which foresaw that the global macro-regions are converging in terms of GDP per capita, the results suggest that this hypothesis was not confirmed.

Based on the methodology used, the study shows that we are not living in a converging world, at least not fully converging. On the contrary, the situation proved to be more complex. The global macro-regions have big disparities internally, usually larger in the macro-regions with lower GDP per capita. On convergence, the gap between the average individual output of the macro-regions and the individual output of its micro-regions is increasing, although the alternative convergence methods offer a more converging perspective.

\section{References}

ATEN, B., \& HESTON, A. (2003). Regional Output Differences in International Perspective. US, University of Pennsylvania Press.

BANERJEE, B., \& JARMUZEK, M. (2009). Anatomy of Regional Disparities in the Slovak Republic. International Monetary Fund, WP/09/145.

BARRO, J., \& SALA-I-MARTIN, X. (1992). Convergence. The Journal of Political Economy, 100(1992), 223-251.

BELL, M. W., HOE EE KHOR, \& KALPANA, K. (1993). China at the Threshold of a Market Economy. Washington, IMF.

BLIZKOVSKY, P. (2012a in preparation). Regional Disparities and Convergences in the European Union. Acta universitatis agriculturae et silviculturae Mendelianae Brunensis, p. 15, Brno, Czech Republic.

BLIZKOVSKY, P. (2012b in preparation). Regional Disparities and Convergences in Asia. Acta universitatis agriculturae et silviculturae Mendelianae Brunensis, p. 17, Brno, Czech Republic.

BLIZKOVSKY, P. (2012c in preparation). Regional Disparities and Convergences in America. Acta universitatis agriculturae et silviculturae Mendelianae Brunensis, p. 15, Brno, Czech Republic. 
CORDOBA, J.C., \& VERDIER, G. (2007). Lucas vs. Lucas: On Inequality and Growth. US: IMF, WP/07/17

DABLA NORIS, E., \& WEBER, S. (2001). Regional Disparities and Transfer Policies in Russia: Theory and Evidence. International Monetary Fund, WP/01/199.

DAS, G. G. (2007). Does Trade and Technology Transmission Facilitate Inequality Convergence? An Inquiry into the Role of Technology in Reducing the Poverty of Nations. International Monetary Fund, WP/07/16.

DOMINGUEZ, J., \& NUNEZ J. (2003). The Evolution of Economic Inequality in the EU Countries During the Nineties. First Meeting of the Society for the Study of Economic Inequality. Madrid.

DUFEK, J., \& MINARIK, B. (2009). Analyza indikatoru pro hodnoceni cilu realizace strategie regionalniho rozvoje v Ceske republice. Brno.

EDERVEEN, S.,GORTER, J., DE MOOIJ, R., \& NAHUIS, R. (2002). Funds and Games, The Economics of the European Cohesion Policy. CPB Netherlands' Bureau for Economic Policy Analysis, The Netherlands.

IMF. (1998). Should Equity Be a Goal of Economic Policy? U.S.: IMF Economic Issues, 16.

IMF. (2007). World economic outlook October 2007: Globalisation and Inequality. World Economic and Financial Surveys.

IRADIAN, G. (2005). Inequality, Poverty, and Growth: Cross-Country Evidence. International Monetary Fund, $\mathrm{WP} / 05 / 28$.

KAUFMAN, M., SWAGEL, P., \& DUNAWAY, S. (2003). Regional Convergence and the Role of Federal Transfers in Canada. International Monetary Fund, WP/03/97.

LUCAS, R.E. (2004). The Industrial Revolution: Past and Future. The Region 2003 Annual Report of the Federal Reserve Bank of Minneapolis, pp. 5-20.

OECD. (2009). How Regions Grow. Policy Brief. Observer OECD, Paris.

SALA-I-MARTIN, X. (1994a). Cross-Sectional Regressions and the Empirics of Economic Growth. USA: Yale University, Economics Working Paper 79.

SALA-I-MARTIN, X. (1994b). Lecture Notes on Economic Growth (I): Introduction to the Literature and Neoclassical Models. Yale University and Universitat Pompeu Fabra, Economics Working Paper 77.

SALA-I-MARTIN, X. (1995). The Classical Approach to Convergence Analysis. Yale University and Universitat Pompeu Fabra, Economics Working Paper 117.

SALA-I-MARTIN, X. (2002). 15 Years of New Growth Economics: What Have We Learnt? Columbia University and Universitat Pompeu Fabra.

SALA-I-MARTIN, X. (2006). The World Distribution of Income: Falling Poverty and Convergence Period. The Quarterly Journal of Economics, CXXI(2).

SERRA, M. I., PAZIMO, M. F., LINDOW, G., SUTTON, B., \& RAMIREZ, G. (2006). Regional Convergence in Latin America and Mexico. International Monetary Fund, WP/06/125.

SUMMERS, R. (1995). The World Distribution of Income: Growth and Inequality. U.S.: University of Pennsylvania. UNDP. (2008). Human Development Report 2009. USA: United Nations Development Programme.

UNEL, B., \& ZEBREGS, H. (2006). The Dynamics of Provincial Growth in China: A Nonparametric Approach. International Monetary Fund, WP/06/55.

VILlAVERDE, J., \& MAZA, A. (2009). Measurement of Regional Economic Disparities. Spain: Department of Economics of the University of Cantabria, UNU-CRISIS Working Papers W-2009/12.

ŽIVĚLOVÁ, I., \& PALÁT, M. (2008). Analýza disparit v kvalitě života mezi okresy jihomoravského kraje. Medzinárodné vedecké dni. Nitra: SPU Nitra, pp.1451-1460.

\section{Notes}

Note 1. http://www.imf.org/external/pubs/ft/weo/2009/02/weodata/weoselgr.aspx

Note 2. Exchange rate used - end of 2008, based on the ECB http://www.ecb.int/stat/exchange/eurofxref/html Note 3. Sources of data identified for each of the macro-regions

Note 4. Exchange rate used - end of the 2008, based on the ECB (http://www.ecb.int/stat/exchange/eurofxref/html 
Table 1. Characteristics of the macro-regions under scrutiny

\begin{tabular}{llcc}
\hline Macro-region & $\begin{array}{l}\text { GDP per capita } \\
\text { (EUR in 2008) (Note 2) }\end{array}$ & $\begin{array}{l}\text { Population } \\
\text { (million, 2008) (Note 3) }\end{array}$ & $\begin{array}{l}\text { Level of economic and } \\
\text { political cooperation }\end{array}$ \\
\hline EU & 25100 & 498 & high \\
NAFTA & 22934 & 444 & medium \\
ASEAN & 1343 & 582 & medium \\
MERCOSUR & 3989 & 239 & medium \\
CIS & 3302 & 273 & low \\
China & 1702 & 1328 & high \\
\hline
\end{tabular}

Table 2. Regions under scrutiny

\begin{tabular}{ccc}
\hline Macro-region & Number of meso-regions (countries) & Number of micro-regions \\
\hline EU & 27 & 97 \\
NAFTA & 3 & 95 \\
ASEAN & 10 & NA \\
MERCOSUR & 4 & NA \\
CIS & 11 & NA \\
China & NA & 31 \\
\hline
\end{tabular}

Table 3. Gini coefficient results for the nominal GDP for the macro-regions

\begin{tabular}{c|ccccccccc}
\hline Region & $\mathbf{2 0 0 0}$ & $\mathbf{2 0 0 1}$ & $\mathbf{2 0 0 2}$ & $\mathbf{2 0 0 3}$ & $\mathbf{2 0 0 4}$ & $\mathbf{2 0 0 5}$ & $\mathbf{2 0 0 6}$ & $\mathbf{2 0 0 7}$ & $\mathbf{2 0 0 8}$ \\
\hline EU & 0.429906 & 0.431124 & 0.482637 & 0.480072 & 0.500184 & 0.490991 & 0.487497 & 0.480871 & 0.473361 \\
NAFTA & 0.665716 & 0.664093 & 0.662589 & 0.662564 & 0.660441 & 0.658001 & 0.656204 & 0.557468 & 0.554857 \\
ASEAN & 0.505318 & 0.507285 & 0.523658 & 0.534122 & 0.530633 & 0.526124 & 0.535954 & 0.532162 & 0.525605 \\
MERCOSU & & & & & & & & & \\
R & 0.566824 & 0.556180 & 0.637615 & 0.629232 & 0.630267 & 0.640199 & 0.644622 & 0.645877 & 0.640363 \\
CIS & 0.777387 & 0.782250 & 0.785491 & 0.789347 & 0.796708 & 0.796872 & 0.796450 & 0.796147 & 0.791757 \\
China & & & & & & & - & - & \\
& 0.421123 & 0.422222 & 0.421131 & 0.424807 & 0.425678 & 0.431357 & 0.433026 & & \\
\hline
\end{tabular}

Table 4. Gini coefficient results for the GDP per capita for the macro-regions

\begin{tabular}{l|ccccccccc}
\hline Region & $\mathbf{2 0 0 0}$ & $\mathbf{2 0 0 1}$ & $\mathbf{2 0 0 2}$ & $\mathbf{2 0 0 3}$ & $\mathbf{2 0 0 4}$ & $\mathbf{2 0 0 5}$ & $\mathbf{2 0 0 6}$ & $\mathbf{2 0 0 7}$ & $\mathbf{2 0 0 8}$ \\
\hline EU & 0.194028 & - & - & 0.266524 & 0.298832 & 0.290175 & 0.288173 & 0.279315 & 0.267136 \\
NAFTA & 0.362137 & 0.362443 & 0.361549 & 0.362472 & 0.361548 & 0.358730 & 0.144886 & 0.146203 & 0.153168 \\
ASEAN & 0.705899 & 0.700549 & 0.695552 & 0.691676 & 0.696835 & 0.694512 & 0.690003 & 0.686478 & 0.675859 \\
MERCOSUR & 0.282790 & 0.297008 & 0.230959 & 0.186471 & 0.176016 & 0.187724 & 0.182582 & 0.176006 & 0.174145 \\
CIS & 0.327352 & 0.356695 & 0.375984 & 0.391114 & 0.405716 & 0.411031 & 0.419465 & 0.411840 & 0.418655 \\
China & 0.335845 & 0.337562 & - & 0.341215 & 0.336475 & 0.317567 & 0.312993 & - & - \\
\hline
\end{tabular}

Table 5. Gini coefficient results for the GDP per capita in PPP/PPS for the macro-regions

\begin{tabular}{c|ccccccccc}
\hline Region & $\mathbf{2 0 0 0}$ & $\mathbf{2 0 0 1}$ & $\mathbf{2 0 0 2}$ & $\mathbf{2 0 0 3}$ & $\mathbf{2 0 0 4}$ & $\mathbf{2 0 0 5}$ & $\mathbf{2 0 0 6}$ & $\mathbf{2 0 0 7}$ & $\mathbf{2 0 0 8}$ \\
\hline EU & 0.163059 & 0.160067 & 0.202156 & 0.198315 & 0.222189 & 0.215727 & 0.213358 & 0.208150 & 0.199492 \\
NAFTA & 0.318454 & 0.320747 & 0.319034 & 0.320894 & 0.323880 & 0.323838 & 0.147407 & 0.147846 & 0.154068 \\
ASEAN & 0.665398 & 0.661948 & 0.659099 & 0.654423 & 0.647482 & 0.639395 & 0.635776 & 0.625278 & 0.619515 \\
MERCOSUR & 0.166275 & 0.154842 & 0.129943 & 0.143224 & 0.152529 & 0.164364 & 0.173316 & 0.178641 & 0.182821 \\
CIS & 0.355402 & 0.353925 & 0.353644 & 0.351766 & 0.351508 & 0.353118 & 0.353212 & 0.357860 & 0.358086 \\
China & - & - & - & - & - & - & - & - & - \\
\hline
\end{tabular}


Table 6. Disparity ranking results of the macro-regions under scrutiny

\begin{tabular}{l|cccccc}
\hline & \multicolumn{3}{|c}{$\begin{array}{c}\text { Macro-regional characteristics (ascendant } \\
\text { order) }\end{array}$} & \multicolumn{3}{c}{ Disparity ranking (ascendant order) } \\
\hline Macro-region & $\begin{array}{c}\text { Population } \\
\mathbf{( 2 0 0 8 )}\end{array}$ & $\begin{array}{c}\text { Nominal } \\
\text { GDP (2008) }\end{array}$ & $\begin{array}{c}\text { GDP per } \\
\text { capita (2008) } \\
\text { (Note 4) }\end{array}$ & $\begin{array}{c}\text { Disparity } \\
\text { (nominal } \\
\text { GDP) }\end{array}$ & $\begin{array}{c}\text { Disparity } \\
\text { (per capita } \\
\text { GDP) }\end{array}$ & $\begin{array}{c}\text { Disparity } \\
\text { (per capita } \\
\text { GDP in } \\
\text { PPP/PPS) }\end{array}$ \\
\hline EU & & & & & & 2 \\
NAFTA & 4 & 6 & 6 & 2 & 4 & 3 \\
ASEAN & 3 & 5 & 5 & 5 & 6 & 6 \\
MERCOSUR & 5 & 1 & 1 & 3 & 1 & 1 \\
CIS & 1 & 2 & 4 & 4 & 5 & 5 \\
China & 2 & 3 & 3 & 6 & 3 & $(4)$ \\
\hline
\end{tabular}

Note: The disparity ranking is based on the average of the Gini coefficient. For China, the ranking in brackets is based on the assumption that the Gini coefficient based on GDP per capita and GDP per capita in PPP are identical.

Table 7. Convergence or divergence results of the macro-regions based on four methods

\begin{tabular}{llllll}
\hline Macro-region & DRC regression & ADRC regression & $\beta_{-}$ & $\begin{array}{l}\sigma_{-} \\
\text {convergence }\end{array}$ & $\begin{array}{l}\text { Convergence } \\
\text { or divergence }\end{array}$ \\
& $\left(\boldsymbol{c}_{2}\right)$ & $\left(c_{2}\right)$ & convergence & & \\
\hline EU & $6.99^{*}$ & 0.37 & -1.32 & $-3.50^{* *}$ & mixed results \\
NAFTA & $6.26^{*}$ & $0.48^{*}$ & 0.14 & $-0.01^{* *}$ & divergence \\
ASEAN & $12.65^{*}$ & $2.98^{*}$ & $-1.90^{* *}$ & $-1.40^{* *}$ & mixed results \\
MERCOSUR & 0.52 & 0.10 & $0.74 * *$ & $1.00^{* *}$ & divergence \\
CIS & $1.40^{*}$ & $0.56^{*}$ & 1.25 & $1.00^{* *}$ & divergence \\
China & $2.37^{*}$ & $0.48^{*}$ & 0.47 & $-1.32^{* *}$ & mixed results \\
\hline
\end{tabular}

* p-value below 0.05

** coefficient of determination $100 r^{2}$ above $50 \%$

Table 8. Overall disparity and convergence results of the macro-regions based on the per capita GDP

\begin{tabular}{llll}
\hline Macro-region & Disparity level/trend & Convergence & $\begin{array}{l}\text { Summary disparity status/overall } \\
\text { trend }\end{array}$ \\
\hline EU & low/growing & mixed results & low disparity/no clear trend \\
NAFTA & medium/status quo & divergence & medium disparity/divergence \\
ASEAN & high/decreasing & mixed results & high disparity/no clear trend \\
MERCOSUR & low/decreasing & divergence & low disparity/divergence \\
CIS & medium/growing & divergence & medium disparity/divergence \\
China & medium/decreasing & mixed results & medium disparity/ no clear trend \\
\hline
\end{tabular}

